\title{
Correction to: Neonatal hypertension: cases, causes, and clinical approach
}

\author{
Michelle C. Starr ${ }^{1}$. Joseph T. Flynn ${ }^{1}$
}

Published online: 27 June 2019

(C) IPNA 2019

\section{Correction to: Pediatric Nephrology (2019) 34:787-799} https://doi.org/10.1007/s00467-018-3977-4

The original version of this article unfortunately contained a mistake. Due to a production error, the wrong "Key summary points" were included. The correct key summary points are listed below.

\section{Key summary points:}

1. Accurate identification of abnormal blood pressure in neonates requires comparison with values obtained in neonates of similar post-menstrual age.

2. Evaluation of a neonate with suspected hypertension begins with careful blood pressure measurement and then proceeds through history, physical examination, laboratory testing, and selected imaging.

3. While many antihypertensive medications have been applied to the treatment of hypertensive neonates, almost none has been systematically studied in this patient population.

4. Available data indicate that most hypertensive neonates will resolve their hypertension over the first $6-$ 12 months of life.

Publisher's note Springer Nature remains neutral with regard to jurisdictional claims in published maps and institutional affiliations.

The online version of the original article can be found at https://doi.org/ $10.1007 / \mathrm{s} 00467-018-3977-4$

Joseph T. Flynn

joseph.flynn@seattlechildrens.org

1 Division of Nephrology, Department of Pediatrics, Seattle Children's Hospital and University of Washington School of Medicine, 4800

Sand Point Way NE, M/S OC.9.820, Seattle, WA 98105, USA 